\title{
Aqui e lá: identidades em questão
}

\author{
Josalba Fabiana dos Santos I UFSE
}

\begin{abstract}
Resumo: A identidade, o identificar-se com, é um conflito constante e num certo sentido insolúvel entre o aqui e o lá. Tanto o aqui como o lá são relativos porque intercambiáveis, não são fixos. Aparentemente opostas, essas categorias espaciais se revelam relativas na definição de fronteiras entre o mesmo e o outro, o igual e o diferente, aquele que faz parte do lugar e o que é estranho ou estrangeiro. Relatos de viagem - de Caminha e Tom Jobim -, poemas - de Gonçalves Dias e Oswald de Andrade - e o romance Cinzas do Norte, de Milton Hatoum, textos aparentemente desconexos, mostram como a viagem e o deslocamento são fundamentais para o fluir de identidades. A fronteira é ambivalente: separa, delimita, é uma barreira, mas também é precisamente o ponto de contato entre o aqui e o lá. A fronteira é porosidade latente, é o encontro. Encontro que potencializa o desencontro e o conflito.

Palavras-chave: Identidade, espaço, fronteira.
\end{abstract}

A identidade se faz de tempo e, acrescente-se, no tempo, pois são as narrativas ficcionais (ou não) acumuladas ao longo das nossas existências, existências individuais e coletivas, que estabelecerão elos, afinidades e aproximações entre as pessoas. E são as histórias ouvidas, lidas e vistas que permitirão que esses elos, afinidades, aproximações e identidades se construam.

Vários pensadores atuais associam a ideia de nação à narrativa, mas talvez seja Eric Hobsbawm um dos seus mais contundentes defensores: "Nación 
sin pasado es un término en sí contradictorio. Lo que hace a una nación es el pasado, lo que justifica a una nación ante las otras es el pasado, y los historiadores son las personas que lo producen." Essa afirmativa isolada pode causar a impressão de que os historiadores sozinhos fazem a nação e que portanto ela é um construto intelectual, uma mera abstração sem ressonância na realidade. Para esclarecer essa questão vamos nos valer de outro teórico: Anthony D. Smith. De modo geral, esse autor, como Hobsbawn, vê uma relação intrínseca entre nação e narrativa, mas deixa claro que a produção intelectual não é suficiente para o estabelecimento da nação:

Las imágenes y las tradiciones que contribuyen a la construcción de naciones no son creaciones artificiales de intelligentsias, jefes o ingenieros culturales, sino el producto de uma compleja interacción de estos creadores, sus condiciones sociales y las herencias étnicas de las poblaciones elegidas. $^{2}$

Portanto, se por um lado narrativas são produzidas ou resgatadas, por outro, é necessário que essas narrativas ecoem ou espelhem a vida de suas populações. Em outras palavras, é preciso que a população se identifique minimamente com essas narrativas. E mais, o passado não é algo estático, que "já estava lá”, um dado que será simplesmente descortinado pelo historiador. O passado está em constante movimento:

No hay nada inmanente o acumulativo en la nación. Una metáfora evolucionista minimiza la discontinuidad, la dislocación y la lucha con fuerzas exteriores que han acompañado con tanta frecuencia el surgimiento de las naciones modernas. ${ }^{3}$

É justamente essa descontinuidade, esse deslocamento e essa luta com forças exteriores - ou o contato com o outro, com o diferente - que permitirão que a história, que as narrativas se transformem. O esquecimento e a memória têm assim um papel fundamental. É preciso esquecer para lembrar - como no título de um dos livros de Drummond. Ou como diria Walter Benjamin, é preciso "fazer

1. HOBSBAWN. Etnicidad y nacionalismo en Europa hoy, p. 173.

2. SMith. ¿Gastronomía o geología? El rol del nacionalismo en la reconstrucción de las naciones, p. 194.

3. SMITH. ¿Gastronomía o geología? El rol del nacionalismo en la reconstrucción de las naciones, p. 199. 
saltar pelos ares o continuum da história", é preciso explodir o "tempo homogêneo e vazio" " para que narrativas não contadas e não ouvidas ainda possam emergir.

Sendo assim, relatos de viagem, poemas, depoimentos, romances têm contribuído para o estabelecimento de uma identidade ou de identidades, que têm se forjado ao longo do tempo e do espaço e que servem de uma forma ou de outra para o processo sempre incompleto de construção da nação. No entanto, nenhuma identidade se faz sem o contraponto do outro, daí optarmos pelo estabelecimento de uma oposição constante na história nacional entre o aqui e o lá, presente desde, pelo menos, a "Carta" de Pero Vaz de Caminha. Nela há um olhar de lá sobre o aqui. A questão é: como esse aqui - aqui do nosso ponto de vista - é confeccionado, elaborado na famosa "Carta". Essa confecção ou elaboração de Caminha se faz a partir de um referente, o universo europeu que ele conhecia, tanto o universo do século XV em si, quanto o conhecimento aí acumulado.

A "Carta", dirigida ao rei de Portugal, trata de muitos aspectos relacionados à nova terra. Iremos nos deter em dois: a natureza e o indígena. Ambos, natureza e indígena, são apresentados como territórios férteis e promissores: "querendo aproveitá-la, tudo dará nela". 5 Na verdade, essa citação se refere especificamente à terra, mas o indígena também é posto como fértil porque Caminha o imagina destituído de fé.

Parece-me gente de tal inocência que, se nós entendêssemos a sua fala e eles a nossa, seriam logo cristãos, visto que não têm nem entendem crença alguma, segundo as aparências. E, portanto, se os degredados que aqui hão de ficar aprenderem bem a sua fala e os entenderem, não duvido que eles, segundo a santa tenção de Vossa Alteza, se farão cristãos e hão de crer na nossa santa fé, à qual praza a Nosso Senhor que os traga, porque certamente esta gente é boa e de bela simplicidade. $\mathrm{E}$ imprimir-se-á facilmente neles todo e qualquer cunho que lhes quiserem $\operatorname{dar}(\ldots)^{6}$

O escrivão crê o índio como uma página em branco aberta à fé cristã, logo para a expansão do cristianismo, que naquele momento era uma das

4. Benjamin. Magia e técnica, arte e política: ensaios sobre literatura e história da cultura, p. 231.

5. CAMINHA. Transcrição atualizada, p. 97.

6. CAMINHA. Transcrição atualizada, p. 94. 
principais justificativas para as grandes navegações empreendidas por portugueses e espanhóis. No entanto, o índio e, especialmente, a índia não são apenas terrenos férteis para a expansão da fé cristã. O índio e a índia, além de objetos exóticos, são sobretudos objetos eróticos. São incontáveis as vezes em que Caminha se refere à nudez indígena. A fascinação e a excitação que aqueles corpos nus causam contrariam ou se adaptam mal à religião pregada.

Por outro lado, a imagem que se constrói da natureza é tão ambígua quanto à do índio. Como já foi dito, Caminha sugere ao rei que a nova terra é esse lugar que "querendo aproveitá-la, tudo dará nela". 7 Porém, afirma também que um dos índios teria dado a entender que havia ouro aqui e que os portugueses assim o entenderam porque esse era o seu maior desejo. A passagem é literalmente a seguinte:

Um deles [um dos indígenas] viu umas contas de rosário, brancas: mostrou que as queria, pegou-as, folgou muito com elas e colocou-as no pescoço. Depois tirou-as e com elas envolveu os braços e acenava para a terra e logo para as contas e para o colar do Capitão, como querendo dizer que dariam ouro por aquilo. Nós assim o traduzíamos porque esse era o nosso maior desejo...

Um pouco adiante essa ambição é reforçada:

O Capitão foi subindo ao longo do rio, que corre sempre próximo da praia. E ali esperou por um velho [índio] que trazia na mão um tronco de jangada. O velho falou enquanto o Capitão estava com ele, diante de todos nós; mas ninguém o entendia e nem ele a nós, por mais pergunta que lhe fizéssemos com respeito a ouro, porque desejávamos saber se o havia na terra.

O ouro não se planta, o ouro é extraído, é levado - do aqui para o lá. Além disso, a busca pelo ouro só reafirma o desejo de pilhagem e de saque que movia as grandes navegações de então. Espanhóis e portugueses só se detinham nas Américas com o objetivo de enriquecer, eles não pretendiam de forma alguma

7. CAMINHA. Transcrição atualizada, p. 97.

8. CAMinHA. Transcrição atualizada, p. 80.

9. CAMINHA. Transcrição atualizada, p. 87. 
se fixar. Infelizmente para Portugal, o pote de ouro do Brasil só chegou aos seus cofres no século XVIII através das Minas Gerais. Antes desse momento, foi preciso procurar muito e encontrar quase nada, de maneira que os colonizadores se viram obrigados muitas vezes a plantar nesta terra na qual nem sempre tudo dava.

Passemos agora ao século XIX. O objeto da nossa rápida reflexão é a "Canção do exílio", primeiro poema do livro Primeiros Cantos, publicado inicialmente em 1846, fruto direto do romantismo, estética nacionalista por excelência. Dessa vez não é mais o português, o estrangeiro, o estranho à nova terra quem falará dela. Gonçalves Dias nasceu no Brasil, mais precisamente no Maranhão. Filho de pai português e mãe mestiça "de cor acobreada, provavelmente produto do cruzamento dos três sangues: branco, negro e índio". 10 A "Canção do exílio" é escrita em 1843, durante o período em que seu autor estuda em Portugal, o que se dá entre os anos de 1838 e 1844. O olhar do poeta sobre o Brasil é muito particular, filho de pai português e mãe mestiça, vivendo seis anos em Portugal e escrevendo a "Canção" nesse período. Mas vamos ao poema propriamente dito.

Minha terra tem palmeiras, Onde canta o Sabiá;

As aves, que aqui gorjeiam, Não gorjeiam como lá.

Nosso céu tem mais estrelas, Nossas várzeas têm mais flores, Nossos bosques têm mais vida, Nossa vida mais amores.

Em cismar, sozinho, à noite, Mais prazer encontro eu lá; Minha terra tem palmeiras, Onde canta o Sabiá.

Minha terra tem primores, Que tais não encontro eu cá; Em cismar - sozinho, à noite Mais prazer encontro eu lá; Minha terra tem palmeiras, Onde canta o Sabiá.

10. Cf. "Cronologia da vida e da obra". DIAS. Poesia e prosa completas, p. 71. 
Não permita Deus que eu morra,

Sem que eu volte para lá;

Sem que desfrute os primores

Que não encontro por cá;

Sem qu'inda aviste as palmeiras,

Onde canta o Sabiá. ${ }^{11}$

Não é nossa intenção fazer do poema uma análise propriamente dita. O que interessa por ora é a oposição - e mais adiante vamos preferir falar com Homi Bhabha: a ambivalência - entre aqui e lá. Na verdade, o uso específico do advérbio aqui só aparece na primeira estrofe, nas demais a oposição se constrói entre um cá e um lá. A opção é evidentemente feita por uma questão sonora: cá rima com lá. Como todos sabem o cá se refere a Portugal e o lá ao Brasil. E quem negaria a lembrança da dicção lusitana implícita e explícita neste cá? Enquanto o lá é posto como atraente, o cá é sempre negativo, é o que não tem ou o que tem menos. Tudo no Brasil é mais: as aves, as estrelas, as flores, a vida e os amores. A "Canção do exílio" é o poema mais parafraseado e parodiado da literatura brasileira. Por ora nos deteremos apenas num exemplo, o "Canto do regresso à pátria":

Minha terra tem palmares

Onde gorjeia o mar

Os passarinhos daqui

Não cantam como os de lá

Minha terra tem mais rosas

$\mathrm{E}$ quase que mais amores

Minha terra tem mais ouro

Minha terra tem mais terra

Ouro terra amor e rosas

Eu quero tudo de lá

Não permita Deus que eu morra

Sem que volte para lá

Não permita Deus que eu morra

Sem que volte pra São Paulo

11. DIAS. Poesia e prosa completas, p. 105-106. 
Sem que veja a Rua 15

E o progresso de São Paulo ${ }^{12}$

Essa paródia de Oswald de Andrade foi publicada em 1925, no livro Pau-Brasil e aparece na seção "Lóide brasileiro". O momento histórico é outro e o estético também. Apesar de marcado ideologicamente pelo nacionalismo, o modernismo, período ao qual o poema se filia, se coloca de forma diferenciada em relação ao romantismo. Tanto o título da seção ("Lóide brasileiro" - referência a uma antiga companhia de navegação), quanto o do poema ("Canto do regresso à pátria”) marcam um trânsito, um movimento. O aqui perde a sua fixidez, torna-se líquido, como é líquida a própria modernidade, segundo Zygmunt Bauman. Outra diferença considerável entre a "Canção do exílio" e o "Canto do regresso à pátria" é a visão da natureza. Enquanto no primeiro há uma louvação incondicional, na paródia de Oswald de Andrade o caso é outro, porque o lá tem "quase que mais amores". Ou seja, bem ao gosto do espírito antropofágico, o poeta canta o Brasil sem esquecer as vantagens europeias. Tanto na Europa quanto no aqui existem muitos amores e o Velho Continente tem uma leve vantagem sobre a nova terra. Isso divide o desejo e o olhar:

La conciencia de no tener historia [ou de termos uma história pequena se comparada à européia], de trabajar con una tradición olvidada y ajena, la conciencia de estar desplazado e inactual. Podríamos llamar a esa situación la mirada estrábica: hay que tener un ojo puesto en la inteligencia europea y el otro puesto en las entrañas de la patria. ${ }^{13}$

O intelectual, em geral, e o escritor, em particular, latino-americano, tem um olho no seu país, na sua própria tradição e outro na Europa - e/ou nos Estados Unidos. Esse olhar estrábico, vesgo colocará esse intelectual numa situação que Homi Bhabha chamará de entre-lugar: ${ }^{14}$ nem aqui nem lá. Esse lugar, de certa forma, é privilegiado porque possibilitará uma visão mais ampla, um deslocamento constante que evita a rigidez do só aqui ou do só lá. E isso combina muito bem com Oswald de Andrade, porque foi um dos nossos grandes poetas do movimento:

12. Andrade citado por SCHWARTZ. Oswald de Andrade, p. 44.

13. PIGLiA. Memoria y tradición, p. 61.

14. BHABHA. Narrando la nación, p. 215. 
viajou por diversos países; foi herdeiro de uma grande fortuna, mas viu-se repentinamente empobrecido após a Queda da Bolsa de Nova York em 1929; casou-se com várias mulheres; enfim, teve uma vida de inconstâncias.

Falando ainda mais um pouco do poema de Oswald: outro verso que se opõe à "Canção do exílio" é "Minha terra tem mais terra". Há pelo menos duas leituras possíveis, sendo que uma, de certa forma, contradiz a outra. A primeira, e talvez a mais evidente, é a da grandiosidade desse lá, que para nós leitores é aqui. Grandiosidade evidente na repetição da palavra terra: o que essa terra tem é muita terra, muito espaço. Mas "Minha terra tem mais terra" como último verso de uma estrofe enumerativa - rosas, amores e ouro - também faz pensar que o poeta não tinha mais o que dizer sobre as grandezas, que ele perdeu o fôlego, que as grandezas não são tantas assim: o que essa/esta terra tem é só terra. Daí inclusive o lado jocoso do poema, a paródia. Outro aspecto interessante a ser ressaltado é que o lá de Gonçalves Dias está voltado à natureza e à expressão dos sentimentos: "Minha terra tem palmeiras". Já o lá de Oswald de Andrade se coloca de forma política: "Minha terra tem palmares". Palmares, nome do famoso quilombo do igualmente famoso Zumbi, presentifica uma ação humana de caráter combativo, distanciando-se da atitude contemplativa romântica. Após esvaziar as qualidades naturais, Oswald tem algo a dizer sobre a interferência desse humano na natureza, o que é ainda mais evidente na última estrofe, na qual a cidade de São Paulo e o seu progresso assumem o lugar central no leque dos benefícios que o Brasil pode oferecer. Note-se ainda a voracidade assumida pelo poeta "Ouro, terra, amor e rosas/Eu quero tudo de lá". Essa voracidade reproduz a ambição da pilhagem colonialista portuguesa, que Gonçalves Dias nem de longe considera na "Canção do exílio" - apesar de registrá-la em outros poemas como em "O canto do Piaga", por exemplo.

Passamos agora a um depoimento de Tom Jobim (1927-1996), transcrito na revista Caros Amigos. ${ }^{15}$ Recém-chegado ao Brasil, após ter morado algum tempo em Nova York, perguntaram ao compositor por que ele voltou e a resposta foi "Lá fora é bom, mas é uma merda. No Brasil é uma merda, mas é bom". Existe uma variante também atribuída a Tom Jobim, que de modo geral não modifica a essência da anterior: "Lá é bom mas é uma merda. Aqui é uma merda mas é bom." Note-se que, segundo o compositor, os Estados Unidos e o Brasil seriam ao mesmo tempo "bons" e "merdas". No entanto, não se pode dizer (não

15. CAROS Amigos, p. 17. 
pelo depoimento) que o aspecto negativo e o positivo de um ou outro país sejam iguais. O que há de diferente entre um lá que é "bom, mas é uma merda" e um aqui que "é uma merda, mas é bom"? Certamente é o identificar-se com - ou, se preferirem, o sentimento de pertença - no qual o Brasil leva vantagem. Na primeira conjunção adversativa, no primeiro mas, que se refere aos Estados Unidos é a "merda" que prevalece. Por outro lado, a segunda conjunção ressalta o lado bom: "No Brasil [estar aqui] é uma merda, mas é [sobretudo] bom." Em outras palavras: os Estados Unidos podem ser bons, mas o Brasil é o melhor. E o que haveria de bom no lá? Provavelmente Tom Jobim se refere à tecnologia, que possibilitou a ele a gravação de discos com uma qualidade melhor; à valorização da cultura, que fez dele um nome consagrado fora do Brasil; e, por extensão, ao muito dinheiro que ele deve ter ganhado. Em contrapartida, o aqui não seria de todo bom, por não ter essas vantagens ora enumeradas, mas ser o lar, a casa do compositor que, após ter sido movido a deixar o seu próprio país por conta de uma série de limitações, lança sobre esse mesmo país um outro olhar mais carinhoso e condescendente. Em contato com outras identidades, Tom Jobim revê a sua própria identidade, torna-se portanto um pouco outro. Volta para o Brasil, talvez, para reencontrar um eu, ou a imagem idealizada de um mesmo, de um igual, de uma identidade, talvez para sempre perdida, talvez jamais existente.

O romance Cinzas do Norte (2005), de Milton Hatoum, também é marcado por essa oposição espacial que estamos discutindo. O autor tem origem árabe, mas nasceu no Amazonas, mais precisamente em Manaus, onde ambienta a maior parte da sua narrativa - dos romances anteriores inclusive: Relato de um certo Oriente e Dois irmãos. A epígrafe de Cinzas do Norte é de João Guimarães Rosa: "Eu sou donde eu nasci. Sou de outros lugares." O romance conta a história de dois amigos: Olavo ou Lavo, seu narrador, e Raimundo ou Mundo, seu protagonista. Lavo corresponde à primeira parte da epígrafe - "Eu sou donde eu nasci” -, pois é o sedentário, é aquele que se fixa à própria terra. Contrariando o senso comum para o qual "Quem viaja tem muito a contar", em Cinzas do Norte quem conta é quem fica: é Lavo quem narra. Mundo, como o próprio nome sugere, é o cosmopolita, relaciona-se à segunda parte da epígrafe - "Sou de outros lugares". Mundo viaja o mundo, outros mundos além de Manaus: primeiro o Rio de Janeiro e depois várias cidades europeias. Espírito inquieto, revoltado, Mundo é artista e precisa sempre aumentar seus horizontes. Lavo não: estuda Direito e exerce a profissão de advogado. É organizado e precisa de uma vida igualmente organizada, vive das leis e na lei. No entanto, como na epígrafe - "Eu sou donde eu nasci. Sou 
de outros lugares" -, ambos, Mundo e Lavo se complementam, se completam. Lavo viaja o mundo através das cartas de seu amigo e Mundo não abandona de fato Manaus, apesar de nunca mais lá voltar, pois continua a "visitá-la" através do contato com Lavo. Lavo é a memória de Mundo: do passado, da família, da cidade: tudo o que Mundo nega, mas que nunca deixa realmente. Em contrapartida, Mundo é o nômade, em trânsito constante, é aquele que propõe a Lavo um universo inapreensível porque sempre em transformação.

Em Cinzas do Norte, o aqui e o lá se colocam como ambivalentes. Já falamos na oposição entre aqui e lá e também anunciamos que preferiríamos falar, com Homi Bhabha, em ambivalência. Na verdade, Bhabha se vale do pensamento de Tom Nairn, que vê a nação como um Janus moderno, o deus de duas faces. O capitalismo, segundo Tom Nairn, reproduziria na nação essa ambiguidade do progresso e do atraso, da riqueza e da pobreza. Bhabha vai adiante dessa leitura economicista e aponta outras ambivalências na nação:

Los heimlich [familiares] placeres del corazón, el unheimlich [estranho] terror del espacio o la raza del Otro; la comodidad de la pertenencia social, las heridas ocultas de la clase; los hábitos del gusto, los poderes de la afiliación política; el sentido del orden social, la sensibilidad de la sexualidad; la ceguera de la burocracia, la perspectiva "legal" [strait] de las instituciones; la calidad de la justicia, el sentido común de la injusticia; la lengua de la ley y el habla del pueblo. ${ }^{16}$

Por extensão a essas palavras, pode-se afirmar que a nação não é apenas o lugar da identidade, mas também o da alteridade. Isto é, todo o aqui emerge de um lá e vice-versa. Para Bhabha, "La 'localidad'de la cultura nacional no es ni unificada ni unitaria en relación consigo misma, ni debe ser vista simplemente como 'otra' en relación con lo que está afuera o más allá de ella”. ${ }^{17}$

Retomando Cinzas do Norte, num certo sentido, poderíamos afirmar que se trata de uma narrativa regionalista amazonense - o aqui - que, no entanto, extrapola essa esfera na medida em que trafega por outros lugares - o lá. Isto é, no avançar da história, o leitor parece se distanciar de Manaus porque Mundo, o protagonista, inicia uma viagem sem volta, primeiro pelo Rio e depois pela Europa, como já dissemos. Parece se distanciar de Manaus, mas não se distancia de verdade,

16. BHABHA. Narrando la nación, p. 213.

17. BHABHA. Narrando la nación, p. 215. 
porque Lavo, que é quem narra, permanece na capital amazonense. No entanto, o que relativiza ainda mais o aqui e o lá no romance é que talvez o aqui-Manaus não soe como aqui para leitores de outros lugares do Brasil. Para a maioria desses leitores, Manaus é um lá que é aqui, uma espécie de cidade ilhada entre um rio, que é o segundo maior do mundo, e uma floresta que é a maior do mundo. É quase como se Manaus não fosse no Brasil, ou como se o Brasil não possuísse Manaus, tão gigantesco é o seu entorno - para não se falar das constantes disputas políticas, inclusive internacionais, a respeito do pertencimento da Amazônia. Por outro lado, quando Mundo está fora, lá na Europa, sozinho, triste, deprimido e doente, vemos o quanto de Manaus ainda permanece nele, o quanto da memória dessa cidade o impregna. Numa relação de empatia com Mundo, que se foi, e também com Lavo, que ficou, o leitor pode sentir que Manaus é sim uma parte dele: um aqui que é, irremediavelmente, um lá. Ainda uma vez, segundo Bhabha: “El 'otro' no está nunca afuera o más allá de nosotros; emerge necesariamente en el discurso cultural, cuando pensamos que hablamos más íntimamente y autóctonamente 'entre nosotros'." 18

Destacamos o papel da viagem em todos os textos aqui comentados: a "Carta" de Pero Vaz de Caminha escrita por um português admirado com um novo mundo, relato no qual a oposição entre um aqui e um lá é bem marcada; a "Canção do exílio", de Gonçalves Dias, um eu brasileiro em Portugal; o "Canto do regresso à pátria”, de Oswald de Andrade, um outro eu brasileiro que está em trânsito, no mar entre a Europa e o Brasil; o depoimento de Tom Jobim - "Lá fora é bom, mas é uma merda. No Brasil é uma merda, mas é bom." -, que retrata o ponto de vista de quem acabara de retornar ao país; e Cinzas do Norte, de Milton Hatoum, que aponta desde a epígrafe claramente para uma ambivalência entre um eu que viaja e um outro eu que fica - "Eu sou donde eu nasci. Sou de outros lugares". Somos uma nação feita de viajantes. A viagem compõe o nosso passado, a nossa história. Os povos indígenas que aqui habitavam se deslocavam constantemente. Os primeiros europeus que aqui chegaram, os portugueses, eram desbravadores viajantes e os que vieram depois, os italianos, os poloneses, os alemães e tantos outros, também se aventuraram numa longa viagem - sem volta para a maioria. Os negros vieram na mais cruel de todas as viagens, um deslocamento compulsório, certamente a grande diáspora da modernidade. Ou seja, temos o olhar feito de diferentes olhares, uma identidade feita de muitas outras identidades,

18. BHABHA. Narrando la nación, p. 216. 
temos uma identidade que não é uma, mas várias, o que indica diversidade. Diversidade feita de harmonias passageiras e tensões permanentes.

Segundo Bhabha, o centro deve ser deslocado pelo periférico. ${ }^{19}$ Abrir dentro dos grandes relatos, das grandes narrativas, espaços intersticiais é o seu interesse, é isso que Bhabha considera de primordial importância para comover e alterar esses relatos, ${ }^{20}$ e, por extensão, os seus leitores e os seus ouvintes. O pintor francês Amédée Ozenfant (1886-1966) já declarara que "O fim da arte é comover... O belo não é prazer mas certa classe de emoção intensiva". ${ }^{21}$ A "mirada estrábica", mencionada por Ricardo Piglia, reúne em harmonia e tensão o aqui e o lá num mesmo olhar. Olhar capaz de comover, mover, impressionar. É essa visão, na aparência distorcida, que nos conduz incessantemente em busca de identidades ameaçadas e abandonadas porque problematizadas por novas identidades sempre flutuantes, sempre em viagem.

Diante desse quadro, Edward Said, em seu ensaio intitulado "Identidade, autoridade e liberdade: o potentado e o viajante" (2003), nos faz pensar no papel da intelectualidade universitária, posicionada numa espécie de entre-lugar:

Uma única identidade dominadora no centro da atividade acadêmica, seja ela ocidental, africana ou asiática, é um confinamento, uma privação. O mundo em que vivemos é feito de numerosas identidades em interação, às vezes de modo harmonioso, às vezes em antítese. Não tratar desse todo (...) é não ter liberdade acadêmica. Não podemos justificar nosso anseio por justiça se defendemos apenas o conhecimento nosso e de nós mesmos. Portanto, nosso modelo de liberdade acadêmica deve ser o migrante ou viajante, pois se no mundo real, fora do universo acadêmico, precisamos ser nós mesmos e apenas isso, dentro da academia precisamos ser capazes de descobrir e viajar entre outros eus, outras identidades, outras variedades da aventura humana. Mas - o que é mais essencial -, nessa descoberta conjunta do eu e do Outro, o papel da academia é transformar o que poderia ser conflito, disputa ou asseveração em reconciliação, reciprocidade, reconhecimento e interação criativa. (...) em vez de ver a procura do conhecimento acadêmico como uma busca

19. BНABHA. Narrando la nación, p. 218

20. BHABHA. Narrando la nación, p. 229.

21. Citado por TELES. Vanguardas européias e modernismo brasileiro, p. 116. 
por coerção e controle sobre os outros, deveríamos considerar o conhecimento algo pelo qual devemos arriscar a identidade e então pensar na liberdade acadêmica como um convite a desistir da identidade na esperança de compreender e talvez até assumir mais de uma. Devemos ver a academia sempre como um lugar para viajar, sem dela nada possuir, mas sentindo-nos sempre em casa em qualquer lugar. ${ }^{22}$

\section{Here and there: identities in question}

Abstract: Identity implies a constant, and in a sense insoluble, conflict between here and there. Both of them are relative because they are interchangeable, therefore not fixed. These apparently antagonistic spatial categories prove to be relative upon the definition of the boundaries between the same and the other, between the equal and the different and between someone who belongs in a place and a stranger or a foreigner. The boundary is ambivalent: it divides, delimits, and imposes a barrier, but it is also precisely the contact point between here and there. The boundary is latent porosity. It is encounter which potentialises disencounter and conflict.

Keywords: Identity, space, boundary.

$$
\text { Referências }
$$

BENJAMIN, Walter. Magia e técnica, arte e política: ensaios sobre literatura e história da cultura. Trad. Sergio Paulo Rouanet. 6. ed. São Paulo: Brasiliense, 1993. v. 1.

BHABHA, Homi. Narrando la nación. In: BRAVO, Álvaro Fernández (Org.). La invención de la nación: lecturas de la identidad de Herder a Homi Bhabha. Buenos Aires: Manantial, 2000. p. 211-219.

CAMINHA, Pero Vaz de. Transcrição atualizada. In: CASTRO, Silvio. A carta de Pero Vaz de Caminha. Porto Alegre: L\&PM, 1996. p. 76-98.

CAROS AMIGOS. São Paulo: Ed. Casa Amarela, n. 126, p. 17, set. 2007.

DIAS, Gonçalves. Poesia e prosa completas. Rio de Janeiro: Nova Aguilar, 1998.

HATOUM, Milton. Cinzas do Norte. São Paulo: Companhia das Letras, 2005.

22. SAID. Identidade, autoridade e liberdade: o potentado e o viajante, p. 206-207. 
HOBSBAWN, Eric. Etnicidad y nacionalismo en Europa hoy. In: BRAVO, Álvaro Fernández (Org.). La invención de la nación: lecturas de la identidad de Herder a Homi Bhabha. Buenos Aires: Manantial, 2000. p. 173-184.

PIGLIA, Ricardo. Memoria y tradición. In: CONGRESSO DA ASSOCIAÇÃO BRASILEIRA DE LiTERATURA COMPARADA - ABRAliC, 2., 1991. Belo Horizonte. Anais do 2. Congresso Abralic. Belo Horizonte: UFMG, 1991, p. 60-66.

SAID, Edward. Identidade, autoridade e liberdade: o potentado e o viajante. In: Reflexões sobre o exílio e outros ensaios. Trad. Pedro Maia Soares. São Paulo: Companhia das Letras, 2003. p.190-208.

SCHWARTZ, Jorge. Oswald de Andrade. 2. ed. São Paulo: Nova Cultural:, 1988. p. 44-45. (Col. Literatura Comentada).

SMITH, Anthony D. ¿Gastronomía o geología? El rol del nacionalismo en la reconstrucción de las naciones. In: BRAVO, Álvaro Fernández (Org.). La invención de la nación: lecturas de la identidad de Herder a Homi Bhabha. Buenos Aires: Manantial, 2000. p. 185-209.

TELES, Gilberto Mendonça. Vanguardas européias e modernismo brasileiro. 7. ed. Petrópolis: Vozes, 1983. 